\title{
Financial Implications in Management of Multidrug Resistant Tuberculosis in India
}

\author{
Dr. Jairaj P Nair, M.D. ${ }^{1}$, Dr. Amita U Athavale ${ }^{2}$, Dr. Vijay S Khatri ${ }^{3}$, Dr. Tanjul Saxena ${ }^{4}$ \\ ${ }^{1}$ Assistant Professor, Department of Chest Medicine \& EPRC, King Edward VII Memorial Hospital, Parel, Mumbai - 400012 \\ ${ }^{2}$ M.D, Professor \& Head \\ ${ }^{3}$ M.D. Associate Professor \\ ${ }^{4} \mathrm{Ph} . \mathrm{D}$ (Assistant Professor - Institute Health Management \& Research, Jaipur)
}

\begin{abstract}
Aim: To calculate total cost incurred by patients for Multi-drug Resistant Tuberculosis (MDR-TB) management and evaluate their financial resources. Financial details regarding MDR-TB management were collected from 30 patients. Average daily drugs cost was Rs. 166.83. Average family monthly income was Rs. 8333.33. Average Per Capita Income was Rs. 1473.67. Financial help for treatment was provided by self-funding, relatives, socio-religious groups, hospital supply \& stockists. Total cost of MDR-TB management is Rs. 140752.50. Including sensitive first line MDR-TB drugs reduces cost remarkably. 90\% of the study group belonged to economically productive age group. Institutional treatment is the cheapest mode.
\end{abstract}

Keywords: Economical, Resources, funding, Cost, Expensive

\section{Introduction}

World Health Organization (WHO) has declared Tuberculosis as a global emergency in 1993. ${ }^{1}$ Multidrug Resistant Tuberculosis (MDR-TB) is defined as resistance of Mycobacterium tuberculosis to Rifampicin and Isoniazid, two of the most effective anti-tubercular drugs for treatment of Tuberculosis. MDR-TB occurs in about 3\% in new tuberculosis cases and $12 \%-17 \%$ in previously treated cases. ${ }^{2}$ Worldwide, there are an estimated 440000 people suffering from MDR-TB (2008) with a mortality of $33 \%{ }^{3}$ Non-inclusion of two important drugs (Rifampicin and Izoniazid) makes the addition of second line drugs mandatory. These drugs are not only expensive, but have weaker potency, need longer course and have toxic sideeffects compared to conventional anti-TB drugs. The indiscriminate use of first line drugs by doctors and treatment defaulted by patients are main causes for rise in MDR-TB cases. ${ }^{1}$ Funding required for MDR-TB control in 2015 will be 16 times higher than that spent in $2010 .^{3}$

Presently in India, MDR-TB is managed by medical colleges and private sector. There was no supply of second line drugs until Directly Observed Treatment- Short course (DOTS) Plus (Government launched programme to treat MDR -TB) was launched in August 2007 on pilot basis. Due to financial constraints, MDR-TB patients are often referred for treatment to medical colleges in Mumbai. Unavailability of these drugs on hospital schedule, forces the patients to buy drugs on their own. Early diagnosis and treatment may prevent some complications and deaths. Migrations, unemployment, alcoholism, are important causes for default in $\mathrm{TB}^{5,6}$. Hence there is an urgency for early diagnosis of MDR-TB and its appropriate management guided by Drug Susceptibility Tests (DST). ${ }^{7}$ The individual costs for various tests and medications incurred for Tuberculosis treatment using Category I, II and III are Rs.1587/-, Rs.1924/- and Rs.1417/- respectively. $^{8}$ The term -Programmatic
Management Of Drug Resistant TB\| (PMDT) (DOTS Plus) is a programme based guideline for MDR - TB diagnosis, management and treatment. These guidelines promote full integration of early TB management and PMDT activities under the Revised National Tuberculosis Control Programme (RNTCP). ${ }^{9}$

In India, the patients treated in the private sector depend on their own family income for the cost of physician, investigations and treatment of MDR-TB. The income of the entire family is drained. These efforts will cure the disease only in $33-50 \%$ patients. The rest may develop Extensively Drug Resistant TB (XDR-TB) or die.

The Editorial of the Indian Journal Of Tuberculosis - 2005 states that the cost of MDRTB is about US\$ 1600 compared to less than US\$ 10 for RNTCP DOTS treatment. ${ }^{10}$ The problems encountered during the treatment of MDR TB is the sustenance of funds and drugs for continuation of treatment; while monitoring the compliance to treatment and managing adverse drug reactions to second line anti TB drugs. There is an urgent need for establishment of more Reference Laboratories to perform mycobacterium culture growth and DST and the development of Rapid On-site line probe assay which will diagnose MDR-TB early especially in new cases. Proper implementation of DOTS regimen can reduce the incidence of non-compliance and those developing MDR-TB can be covered under DOTS PLUS regimen to reduce financial burden on the family.

\section{Objectives}

1) To study the total cost incurred by the patients in the management of MDR-TB

2) To determine the various financial resources used by and available for MDR-TB patients. 


\section{International Journal of Science and Research (IJSR) \\ ISSN (Online): 2319-7064}

Index Copernicus Value (2015): 78.96 | Impact Factor (2015): 6.391

\section{Methods}

Research Design: Descriptive

Sample Size: Thirty patients

Inclusion criteria: All patients diagnosed as MDR-TB following up for management with the department in this Institute.

\section{Exclusion criteria: Between 18 to 60 yrs of age}

After written informed consent, data was collected from the patients. The detailed evaluation of the cost in terms of cost incurred for diagnosis, treatment and follow-up visits in this institute was recorded. The sources of income and per capita income were calculated. Detailed history about the source for procurement of medicines required for MDR-TB treatment was collected.

Sampling method: Non-Probability Purposive sampling

Study Period: Twenty Four months from Ethics Committee approval

\section{Results}

Thirty patients were enrolled referred from various departments of the hospital for management MDR -TB (confirmed by growth of Mycobacteria on culture - resistant to Isoniazid and Rifampicin - from a WHO accredited laboratory on AFB Mycobacterium Growth in Indicator Tubes - MGIT). There were nineteen (63.3\%) females and eleven males (36.7\%). 90\% of the patients were below 40 yrs of age with mean weight of $43.2 \mathrm{~kg}$. There were 21 cases $(70 \%)$ of Pulmonary Tuberculosis. While 5 cases $(16.7 \%)$ were Pott's Spine (Spine TB). Rest of cases was one each of Skin \& joint, Lymph node, Calcaneal \& disseminated form of TB.

All the 30 people were previously treated with first line Anti-TB at least once and 7 people (23.3\%) gave history of anti-TB treatment twice in the past accounting for drug resistance. The following resistance pattern was noted:

All cases were MDR -TB (resistant to Izoniazid \& Rifampicin). Pyrazinamide had a high sensitivity.

Figure 1

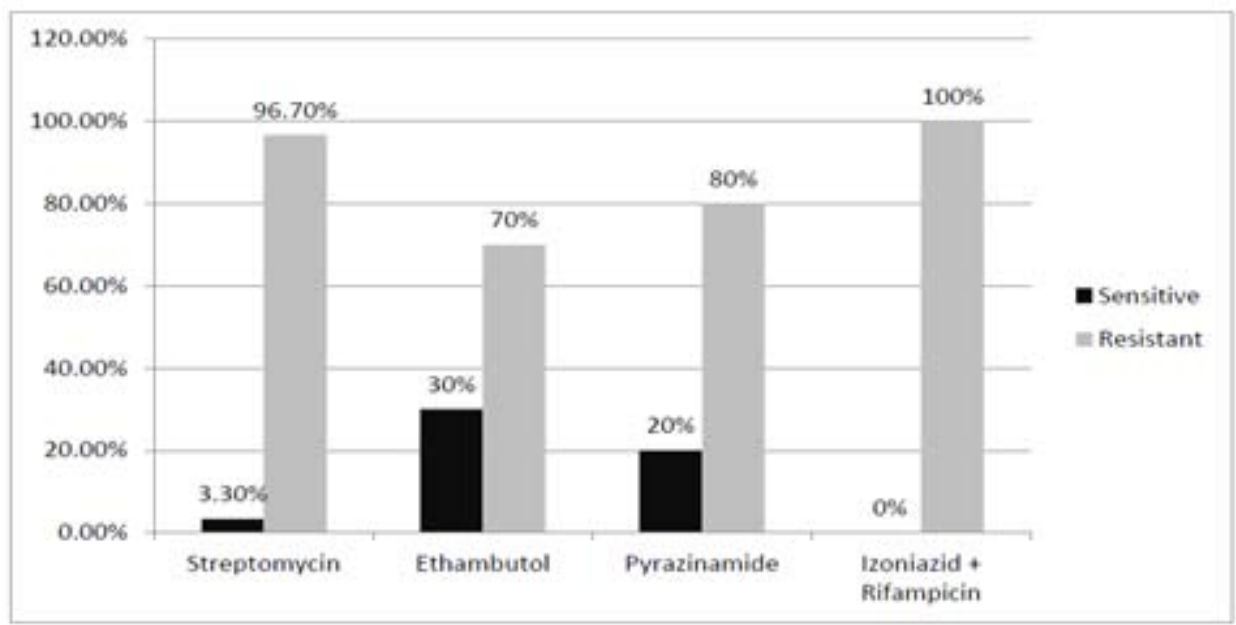

Dnug Susceptibility to First line Anti- TB drug (N=30 cases)

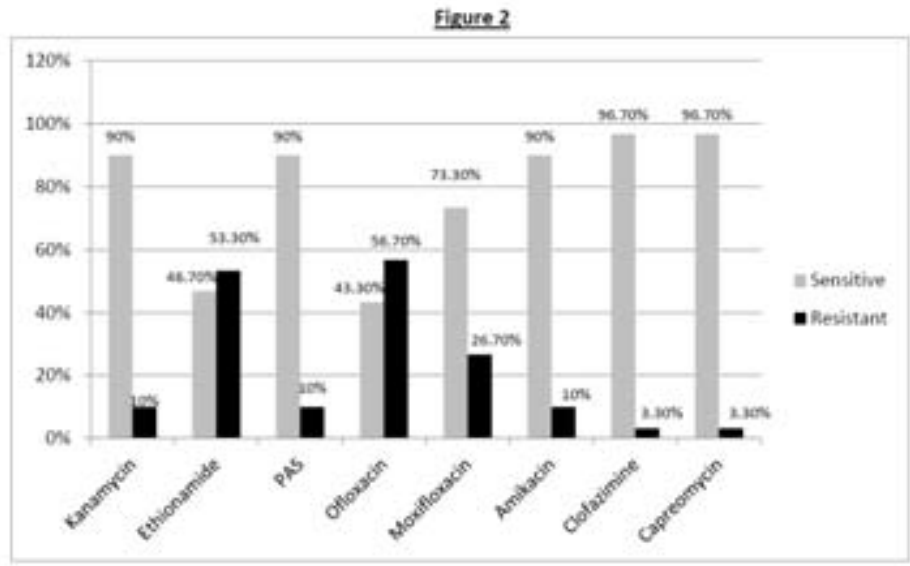

Drug Susceptibility Report - Second Line Anti - TB drugs ( $N=30$ cases)

Radiology costs included the charges for X-Ray Chest, CT Scan Chest \& MRI Spine. The cost of X-Ray chest is Rs.30/- in government setup as against Rs.150-200 per X- ray chest in the private sector. Similarly, CT Scan Chest charges in the Institute were Rs. 1200/- as against Rs.4000 5000 per Scan in the private sector. For Pott's Spine cases, 


\section{International Journal of Science and Research (IJSR) \\ ISSN (Online): 2319-7064 \\ Index Copernicus Value (2015): 78.96 | Impact Factor (2015): 6.391}

MRI is advised for both diagnosis and response to treatment. In this Institute, MRI spine costs Rs.2500/- per scan as against Rs.7000/- in the private sector. Buying these drugs were a major hurdle for the patients on MDR-TB regimens. Patients were treated with injectable aminoglycosides daily in the initial Intensive phase (6 months). This included charges for purchasing injections and charges for the doctor/nurse for their daily services. Those staying close to DOTS centre took the injections from the DOTS centre cutting down on Rs.20/- per injection which amounted to Rs.600/- per month. The regimen was formulated based on the Drug Sensitivity report. It was noted that addition of sensitive first line drugs decreased the cost of the treatment remarkably.

Figure 3

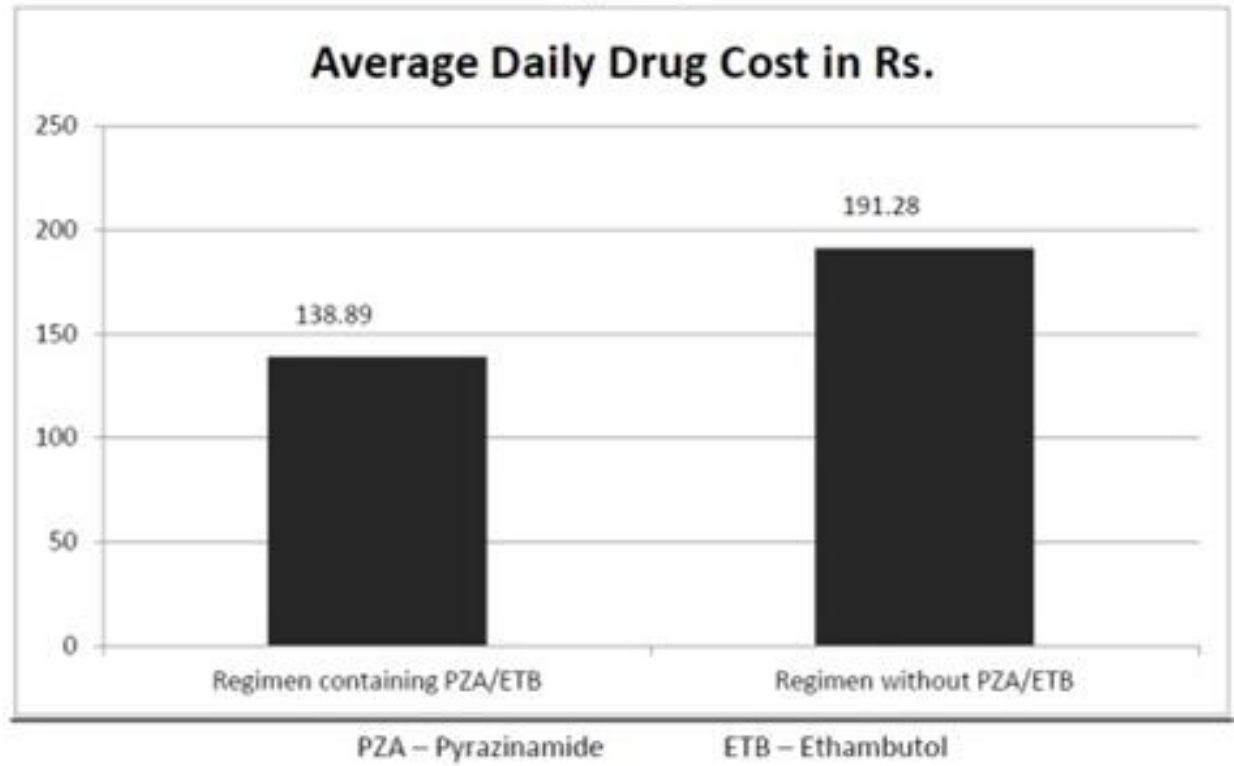

Comparison of Average Daily Cost of Drugs with/without PZA/ETB

Figure 4

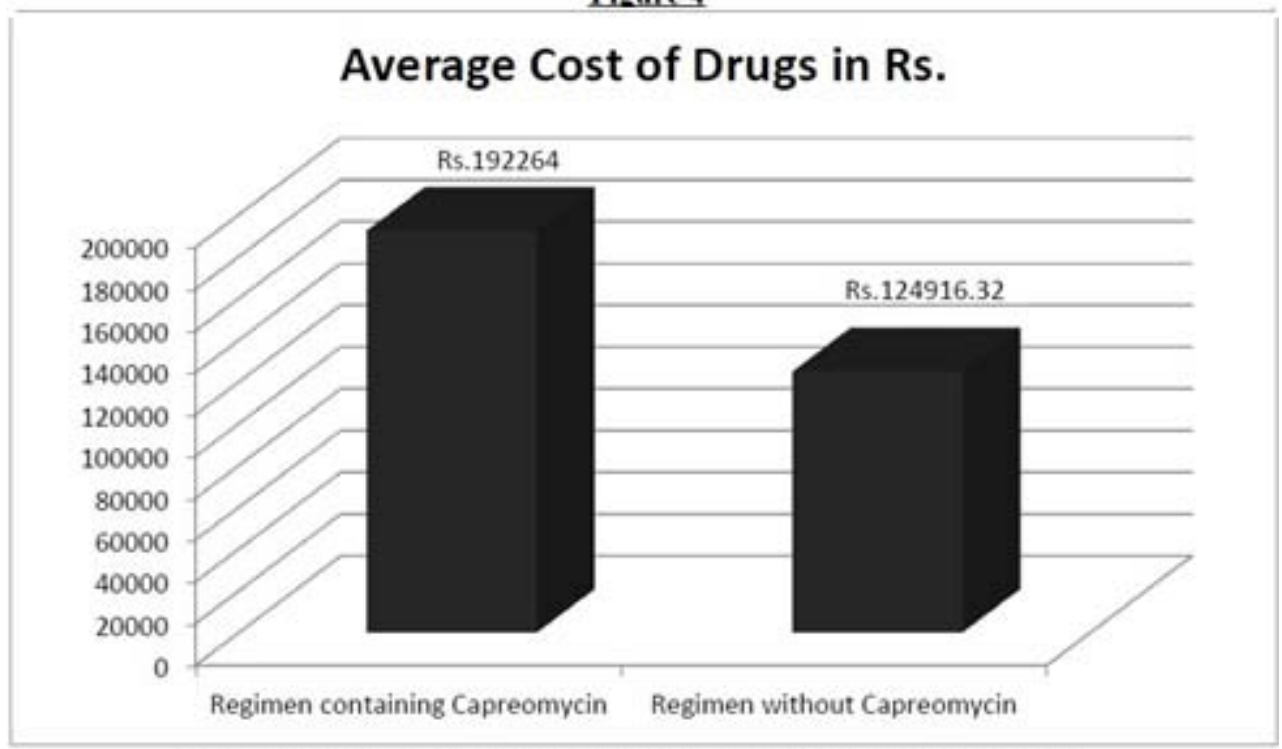

Comparison of average cost of drugs with/ without Capreomycin

The total expenditure on MDR Treatment was Rs.140752.50 for the entire duration of 24 months treatment. However, this excludes charges for doctors, nurses, laboratories and some drugs available on hospital schedule. The indirect cost (which includes amount spent by hospital on the patient in terms of salaries of hospital employees and infrastructure) has been excluded. The total cost of drugs alone was Rs. 129406.17. The average total daily cost of drug was Rs.166.83. This excludes the cost of injectable second line anti-TB (Kanamycin, Amikacin \& Capreomycin) given for 6 months only (180 doses) amounting to average of Rs. 12286.56 for total treatment.

However, the following points must be noted while formulating the MDR - TB regimen in cost management:

a) Two drugs should not belong to same drug family - they cause added toxicity with no additional benefit

b) Potent drugs should be preferred over less potent drugs in the regimen

c) Drugs with lesser side effects should be chosen (better tolerated by the patient) 


\section{International Journal of Science and Research (IJSR) \\ ISSN (Online): 2319-7064 \\ Index Copernicus Value (2015): 78.96 | Impact Factor (2015): 6.391}

d) At least 3-4 drugs (not used earlier) must be added to ensure good potent regimen

e) Certain drugs are potent (bactericidal) and cheap (Levofloxacin is an excellent anti-TB drug which is bactericidal and also cheap -Rs.7/- per day)

f) Drugs available in hospital supply should be preferred to bring down the cost of the treatment (Amikacin is available in hospital supply; although it is expensive when purchased by the patient).

g) Clofazimine though less potent has an excellent sensitivity and is also cheap. It is better tolerated by the patient (except skin discoloration). ${ }^{9}$

\section{Sources of Funds}

The mean average family income was Rs.8333.33 per month. The mean family size was 5.47. The per capita income of the group was Rs.1473.67

The social \& religious groups contributed about Rs. 71380/in all.

Certain drugs were available as antibiotics from hospital supply. (eg - Injection Amikacin and Azithromycin for indoor patients and oral Levofloxacin for indoor and outdoor patients (OPD).

Most of the patients contributed for second line drugs from their own household income. Some patients borrowed funds from their relatives and friends on loan basis.

The Hospital Poor Box Fund contributed to some funds in procuring medicines for some of the indoor patients. The patients were assessed by Medical social worker; based on their socioeconomic status provided discounts up to 50-75\%; the rest being provided from the Hospital Poor Box Fund.

The pharmaceutical companies and the medical stores helped patients in procuring the drugs.

Patients would get up to $10-20 \%$ discounts when they directly procured drugs from the wholesalers of the companies (Stockists). Some patients brought medicines from medical stores around the hospital procured the medicines for a discount of 5-10\%. This reduction on Maximum Retail Price (MRP) would definitely bring down the cost of total treatment by $10 \%$. Some companies provided drug samples which helped patients tide over few days until money was arranged leading to uninterrupted drug supply.

\section{Discussion}

The present study was conducted to determine the total cost of MDR-TB management. In thirteen countries of Central and Eastern Europe (CEEUR), the frequency of MDR-TB was higher in all age groups compared with the rest of the countries (all high-income) and peaked in young adulthood ${ }^{3}$. In this study, the age group was mainly in less than 40 years. The present study excludes indirect cost loss of daily wages and the amount spent by the hospital on the patient for either OPD consultation or indoor stay; unlike - Thorax 2000\| UK study, ${ }^{8}$ where the indirect costs borne by the hospital (OPD
\& IPD services) were added to the cost incurred in treating MDR TB. TB inflicts considerable economic burden on the overall health system. This information is vital for policy makers and planners to allocate adequately to the programme. ${ }^{10,11}$ Though Clofazimine is considered as a weak anti- TB drug, its response in combination with other anti-TB drugs has been found to be good.12 In this study, Clofazimine was found to cut down the cost of the entire regimen and well tolerated the drug. In a study in the UK, cost of sensitive tuberculosis was 6040 pounds; while cost of resistant tuberculosis was in excess of 60,000 pounds. $^{8}$

In a Bangalore study amongst the TB patients, the percentage of patients belonging to low and middle standard of living were $50 \%$ and $39 \%$ respectively; while the household per capita income of $77 \%$ was less than US\$1 per day. The costs incurred for diagnosis amounted to US\$145; while during RNTCP treatment the cost was US\$21. Those people treated outside

RNTCP was US\$127. This study shows the economic plight of the Indian population suffering from Tuberculosis. ${ }^{14}$ International TB funding suffered a setback on contributions from UK. ${ }^{15}$ In a study conducted in Ecuador by the Pediatrics Department (Canada), among 104 non-MDR-TB patients, average cost of 104 non-MDR TB treatment was US $\$ 960$ per patient, as against that the average cost of 14 MDR patients was US\$6880. ${ }^{16}$

DOTS PLUS is the new armamentarium in the RNTCP since 2007 (pilot study) which treats drug resistant tuberculosis in India. The patient can be included only if the sputum shows growth of mycobacteria resistant to Isoniazid and Rifampicin. (Laboratory Accredited by WHO). Patients are registered under DOTS PLUS programme for free treatment of MDR TB for a 2 year period. DOTS PLUS can lead to catastrophic effects in future if not implemented properly. Implementation of DOTS is the need of the hour.

\section{Conclusions}

1) The average treatment cost of MDR-TB is Rs. 140752.50.This includes total drug costs of Rs. 129406.17

2) The average total daily cost of drugs is Rs.166.83.

3) The total cost of treatment is reduced remarkably by including sensitive first line drugs like Pyrazinamide and Ethambutol. They are also more potent and less toxic than the second line drugs.

4) The non-drug expenditure of treatment like blood and microbiological investigations, radiological monitoring will cut down cost in a teaching hospital than private sector.

5) $90 \%$ of patients were below forty years of age (an economically productive age group).

6) Average monthly income of the family is Rs. 8333.33; while per capita income is Rs. 1473.67

7) Major contribution towards treatment expenditure comes from patient's personal income. Additional contributions come from socio-religious groups, hospital poor box fund, pharmaceutical companies and medical stores.

\section{Volume 6 Issue 1, January 2017




\section{International Journal of Science and Research (IJSR) \\ ISSN (Online): 2319-7064}

Index Copernicus Value (2015): 78.96 | Impact Factor (2015): 6.391

There were no financial assistance received for this study from any Institute or pharmaceutical company.

\section{References}

[1] Reuters. Los Angeles Times. Collections. WHO Calls Tuberculosis a Global Emergency: Health statistics [Internet].1993 April 24. Available on http://articles.latimes.com/1993-04- 24/news/mn26683_1_global-emergency

[2] Empowered Procurement Wing - An Initiative of the Ministry of Health and Family Welfare. Government of India. RNTCP Launches Cat IV (DOTS Plus) treatment for Multidrug Resistant TB. 2009.Available on http://mohfw-epw.gov.in

[3] World Health Organization. Media Centre. Drugresistant tuberculosis now at record levels. News release. 2010 March 18. Geneva/Washington DC. Available http://www.who.int/mediacentre/news/releases/2010/dr ug_resistant_tb_20100318/en/index.html

[4] TBC India. Directorate General of Health Services \& Ministry of Health and Family Welfare. [Internet].2010 January. Available www.tbcindia.nic.in/documents.html\#

[5] Singla R, Sarin R, Khalid UK et al. Seven-year DOTSPlus pilot experience in India: results, constraints and issues. Int J Tuberc Lung Dis. 2009 Aug;13(8):976-81

[6] Hasker E, Khodjikhanov M, Usarova S, Asamidinov U, Yuldashova U, van der Werf MJ, et al. Default from tuberculosis treatment in Tashkent, Uzbekistan; who are these defaulters and why do they default? BMC Infect Dis. 2008 Jul 22; 8: 97.

[7] World Health Organization. Summary Report of the Expert Group Meeting on Liquid Culture Media, Geneva.2007 March 26.[Internet]. Available on http://www.who.int/tb/laboratory/use_of_liquid_tb_cult ure_summary_report.pdf

[8] White VL, Moore-Gillon J. Resource implications of patients with multidrug resistant tuberculosis. Thorax. 2000 Nov; 55(11):962-3.

[9] Revised National Tuberculosis Control Programme Guidelines on Programmatic Management of Drug Resistant TB (PMDT) in India. May 2012. Central TB Division, Directorate General of Health Services, Ministry of Health \& Family (New Delhi).

[10] Muniandi M, Rajeswari R, Balasubramanian R. Estimating provider cost for treating patients with tuberculosis under RNTCP. Indian Journal of Tuberculosis 2006;53:12-17

[11] Agarwal SP. The Editorial of the Indian Journal Of Tuberculosis. Indian Journal of Tuberculosis 2005; 52:175-177

[12] Xu HB, Jiang RH and Xiao HP. Clofazimine in the treatment of multidrug-resistant tuberculosis. Clin Microbiol Infect. 2012 Nov; 18(11):1104-10

[13] World Health Organization. Multidrug and extensively drug-resistant TB (M/XDR-TB) Global report on surveillance and response. 2010 March. [Internet] Available http://whqlibdoc.who.int/publications/2010/9789241599 191_eng.pdf
[14]Pantoja A, Floyd K, Unnikrishnan KP, Jitendra R, Padma MR, Lal SS et al. Economic evaluation of public-private mix for tuberculosis care and control, India. Part I. Socioeconomic profile and costs among tuberculosis patients Int J Tuberc Lung Dis. 2009 Jun;13(6):698-704.

[15] International Development Committee Written evidence submitted by UK Consortium on AIDS and International Development-TB/HIV Working Group. Prepared on 21st May 2012.[Internet]. Available on http://www.publications.parliament.uk/pa/cm201213/c mselect/cmintdev/126/126we05.ht $\mathrm{M}$ delhidude_sharma@yahoo.com

[16] Rouzier VA, Oxlade O, Verduga R, Gresely L, Menzies D. Patient and family costs associated with tuberculosis, including multidrug-resistant tuberculosis, in Ecuador. Int J Tuberc Lung Dis. 2010 Oct; 14(10):1316-22. 